DOI 10.5216/ia.v45i3.65164

\title{
ESTUDOS EM FORMAÇÃO DE PROFESSORES REALIZADOS NO MESTRADO EM EDUCAÇÃO DA FFP/UERJ: QUAIS SUAS CONTRIBUIÇÕES?
}

\author{
Carlos César de Oliveira \\ Pontifícia Universidade Católica do Rio de Janeiro (PUC-Rio), Rio de Janeiro, Brasil \\ HelenA AMARAL DA FONTOURA \\ Universidade do Estado do Rio de Janeiro (UERJ), Rio de Janeiro, Brasil
}

\begin{abstract}
Resumo: O estudo em questão tem como propósito suscitar diálogos acerca da formação de professores, tomando como referência as pesquisas realizadas por estudantes do curso de Mestrado em Educação Processos Formativos e Desigualdades Sociais da Faculdade de Formação de Professores da Universidade do Estado do Rio de Janeiro - FFP/UERJ. Por meio do levantamento bibliográfico, procuramos nos debruçar sobre as discussões realizadas por estudantes do programa - entre os anos de 2010 e 2018 -, reconhecendo a potência de um "quefazer" (FREIRE, 1987; 2007) que envolve não somente a ação de pesquisar e refletir sobre a prática docente, mas uma nova ação que consiste em (re)pensar a partir do processo decorrente da pesquisa, isto é, aprender "nele e com ele". Nesse sentido, as questões aqui levantadas em diálogo com estudiosos como Nóvoa (1992; 1995) e Freire $(1996$; 1997) pretendem contribuir teórica e metodologicamente com o campo da Formação de Professores, tomando como base para análise os seguintes eixos: inserção do profissional docente, desenvolvimento do profissional docente, Formação Inicial, Formação Continuada e Docência Universitária.
\end{abstract}

Palavras-chave: Formação de Professores. Professor-pesquisador. Prática Docente. Diálogo. Política.

\section{PRIMEIRAS PALAVRAS}

A formação de professores deve criar as condições para uma renovação, uma recomposição, do trabalho pedagógico, nos planos individual e coletivo. Para isso, é necessário que os professores realizem estudos de análise das realidades escolares e do trabalho docente. Antonio Nóvoa.

O Programa de Pós-Graduação em Educação (PPGEdu), da Faculdade de Formação de Professores da Universidade do Rio de Janeiro - FFP/UERJ, situado no campus da instituição, no Bairro Patronato, município de São Gonçalo - RJ, no ano de 2019 comemorou os seus 10 (dez) anos de existência e serviço dedicado à formação de 
professores. Quando criado, em 2009, o PPGEdu assumiu um compromisso com "Educação - Processos Formativos e Desigualdades Sociais", contribuindo, sobretudo, para a formação de professoras/es da região de São Gonçalo e adjacências, conforme demonstraremos no decorrer do estudo. Assim, ao longo desses 10 anos, o programa tem investido na formação de mestres, a partir de duas linhas de pesquisa: "Formação de Professores, História, Memória e Práticas Educativas" e "Políticas, Direitos e Desigualdades" (PPGEdu, 2019), que, de forma articulada, vem resultando em estudos acerca da educação, tendo em vista que "formação" e "política" caminham juntas, como partes do processo educacional.

No que se refere aos objetivos do programa, convém destacar que ele procura "contribuir para a produção do conhecimento qualificado no campo dos processos formativos, na perspectiva da formação humana, bem como das políticas que possam propor dispositivos de enfrentamentos em face das desigualdades sociais" (PPGEdu, 2019, n.p.).

Ocorre que, no ano comemorativo dos seus 10 anos de existência, o PPGEdu, após formar mais de $200^{1}$ mestres, inicia a sua primeira turma de Doutorado em Educação, reforçando o seu propósito de

oferecer o ensino em nível de Mestrado Acadêmico e Doutorado, a fim de promover o aprimoramento de pesquisadores e educadores para a atuação em diversos níveis de ensino, variados contextos educativos, movimentos sociais, na gestão de políticas públicas, investigação científica e produção de conhecimento no campo da Educação (PPGEdu, Regulamento, Art. 1\%).

Partindo desse pressuposto, afirmamos que o programa enseja "uma formação teórico-investigativa" aos seus estudantes, com o intuito de "fortalecer política e epistemologicamente seu compromisso com a educação", contribuindo, assim, "para a superação dos desafios colocados à democratização da sociedade brasileira" (PPGEdu, Regulamento, Art. $1^{\circ}$, parág. único).

Face a isto, nos inspiramos nos estudos de Messina (1999), Vosgerau e Romanowski (2014), bem como em André (2010), ao discutir a Formação de Professores como um campo de estudos. Em diálogo com a autora, queremos conhecer mais e melhor os professores-pesquisadores da FFP/UERJ e suas pesquisas sobre Formação de Professores. A partir disso, surge o nosso desejo de identificar e analisar quais das dissertações de mestrado produzidas pelos estudantes do programa, de um total de 178 (cento e setenta e oito), tiveram como objeto específico a "formação de professores". Para tanto, o levantamento considerou as pesquisas concluídas entre os anos de $2010 \mathrm{e}$ $2018^{2}$, visto que as/os estudantes da primeira turma, iniciada em 2009, concluíram as suas pesquisas em 2010.

Na tentativa de responder à inquietação de como a "Formação de Professores" vem sendo objeto de estudo para pesquisadores/as do PPGEdu, optamos por esse recorte temático por acreditar que os estudos realizados podem oferecer elementos para um potente diálogo acerca da formação. Por meio dele, vislumbramos promover uma discussão - sob diversos olhares - a respeito da formação docente, tendo em vista 
OLIVEIRA, C. C. de; FONTOURA, H. A. da.

a inserção ou interesse de cada pesquisador estudado (e do Programa) quanto à temática em questão.

Sobre esse assunto, Vosgerau e Romanowski (2014) nos sugerem que

Os estudos de revisão consistem em organizar, esclarecer e resumir as principais obras existentes, bem como fornecer citações completas abrangendo o espectro de literatura relevante em uma área. As revisões de literatura podem apresentar uma revisão para fornecer um panorama histórico sobre um tema ou assunto considerando as publicações em um campo (p. 67).

Além disso, tais estudos "favorecem examinar as contribuições das pesquisas, na perspectiva da definição da área, do campo e das disciplinas que o constituem, avaliação do acumulado da área, apontando as necessidades de melhoria do estatuto teórico metodológico, e mesmo as tendências de investigação" (VOSGERAU; ROMANOWSKI, 2014, p. 67). É com esse pensamento que o presente estudo surge, com o intuito de organizar e sistematizar as dissertações já existentes, apresentando um panorama das produções realizadas por estudantes do programa e suas contribuições para o campo da "Formação de Professores", que, inclusive, serve como eixo para uma das linhas de pesquisa, conforme já mencionamos.

Assim, através da literatura produzida pelas/os, hoje, mestres, egressas/os do PPGEdu, buscamos identificar quais pesquisas tiveram a formação docente como seu objeto de estudo. Diante disso, problematizamos o tema e, à luz dos pesquisadores e pesquisadoras que tiveram uma inserção no Programa, apresentamos, em seguida, algumas considerações, com a finalidade de enaltecer a importância das pesquisas nesse campo, especialmente a partir da sua inserção social e da sua capacidade de contribuir para suscitar "novos caminhos e possibilidades para trabalhar a formação" (VOSGERAU; ROMANOWSKI, 2014, p. 167). Afinal, "os estudos que têm por finalidade a realização desta revisão permitem a compreensão do movimento da área, sua configuração, propensões teóricas metodológicas, análise crítica indicando tendências, recorrências e lacunas" (VOSGERAU; ROMANOWSKI, 2014, p. 167).

Entretanto, queremos esclarecer que, embora tenhamos elegido apenas os trabalhos voltados para o campo da "Formação de Professores", compreendemos que todos os trabalhos desenvolvidos ao longo dos 10 (dez) anos do PPGEdu apresentam relevância no âmbito da formação, visto que foram pesquisas elaboradas por professores que, ao pesquisar, estão num constante processo de "reflexão acerca da sua prática" (FREIRE, 1987; 1996; 2018), logo, em/de formação.

Quanto à metodologia adotada, reconhecemos que existem variadas denominações acerca dos estudos que envolvem revisão de literatura, conforme destacam Vosgerau e Romanowski (2014). Diante disso, a metodologia por nós utilizada se insere no que Messina (1999) chama de "estado da arte". Para essa autora,

Un estado del arte es un mapa que nos permite continuar caminando; un estado del arte es también una posibilidad de hilvanar discursos que en una primera mirada se presentan como discontinuos o contradictorios. En un estado del arte está presente la posibilidad de contribuir a la teoria y a la práctica de algo, en este caso de la formación docente (MESSINA, 1999, p. 145) 3 
Brandão, Baeta e Rocha (1986, p. 7, apud VOSGERAU e ROMANOWSKI, 2014, p. 171) afirmam que os estudos que adotam o "estado da arte" ou "estado do conhecimento" "têm por objetivo realizar levantamentos do que se conhece sobre um determinado assunto a partir das pesquisas realizadas em uma determinada área". Com base nos fundamentos apresentados pelos autores, destacamos que o procedimento metodológico adotado contribui para mapear os estudos realizados pelo PPGEdu acerca da "Formação de Professores", podendo servir como base ou como estímulo para estudos futuros, seja por parte de estudantes ou de professores.

Ressaltamos que a processualidade da pesquisa resultou em duas etapas: a primeira envolveu a catalogação (por meio do Excel), através da qual as dissertações produzidas por estudantes do PPGEdu, entre os anos de 2010 e 2018, foram organizadas. Inicialmente, atentamos para o ano, título, autor/a e orientador/a. É importante lembrar que essa organização inicial possibilitou, ainda, mapear os estudos por linha de pesquisa.

Em seguida, foram selecionadas 17 (dezessete) dissertações que adotaram a "Formação de Professores" como objeto de estudo. A partir de então, deu-se início a um trabalho de leitura dos resumos e das considerações finais, especificamente a fim de identificar os caminhos teórico-metodológicos adotados, na tentativa de construir uma análise acerca das/os docentes que - em formação - se propuseram a estudar e problematizar a sua prática.

Entendemos que, ao promover um debate sobre essa temática, evidenciamos as contribuições do PPGEdu no fortalecimento da Faculdade de Formação de Professores de São Gonçalo (FFP/UERJ), tornando-a um "centro de referência na produção de conhecimentos para a região onde está inserida" (PPGEdu, Regulamento, Art. $2^{\circ}$, p. IV).

Por fim, considerando que um estado da arte "não se restringe a identificar a produção, mas analisá-la, categorizá-la e revelar os múltiplos enfoques e perspectivas" (VOSGERAU; ROMANOWSKI, 2014, p. 172), este estudo foi estruturado em eixos temáticos (categorias), pensados a partir dos títulos e palavras-chaves apresentadas pelos sujeitos estudados. São eles: "Inserção do Profissional Docente", "Formação Docente", "Formação Continuada" e "Docência Universitária", conforme apresentaremos a seguir.

\section{EIXO 1 - INSERÇÃO DO PROFISSIONAL DOCENTE.}

A inserção do profissional no mercado é, ainda, um desafio para as/os novas/os docentes que, ao chegar nas instituições de ensino, enfrentam grandes dificuldades, tendo em vista a distância que ainda existe entre a academia e a escola. Nesse sentido, discutir a inserção docente se torna algo pertinente e necessário. Por esse motivo, incitamos um debate sobre o tema a partir de 03 (três) estudos realizados pelo programa ${ }^{4}$.

No decorrer deste estudo, identificamos que Fernandes (2011), Costa (2015) e Leite (2015) adensam essa discussão nos trabalhos apresentados junto ao PPGEdu. Assim, enquanto Fernandes problematiza os "egressos das licenciaturas da FFP/UERJ", 
Costa se volta para "a residência pedagógica de uma escola do município de Niterói $R J$ ". E, com uma discussão mais específica em torno dos professores de Ciências, Leite, à luz da "Pedagogia da Cooperação", procura analisar a formação das/os professoras/es desse campo. Portanto, numa breve síntese, apresentaremos algumas ideias sobre cada estudo. Ao final, destacaremos, de forma geral, os referenciais teórico-metodológicos adotados.

Para Fernandes (2011, p. 9), o propósito do estudo consiste em "estabelecer um diálogo e acompanhar o percurso profissional dos egressos das licenciaturas da FFP, verificando a situação ocupacional dos mesmos após o término do curso e os benefícios advindos da titulação". De forma analítica, a autora destaca "a partir da ótica dos egressos, as contribuições e impactos do processo formativo acadêmico na atuação profissional e na vida pessoal e social" (FERNANDES, 2011, p. 9), evidenciando "as demandas por formação continuada e a realização de cursos de pós-graduação" (FERNANDES, 2011, p. 9) apresentadas pelos egressos.

Por fim, em suas considerações, afirma:

\begin{abstract}
Estudar a universidade através dos egressos possibilitou verificar as relações estabelecidas com a sociedade e repensar a formação inicial e continuada de professores a partir do contexto de seu trabalho, das situações vivenciadas no cotidiano das escolas, das considerações acerca da realidade enfrentada após seu ingresso na vida profissional, além de suscitar diálogos com vistas a estabelecer uma relação orgânica entre a universidade, escola e sociedade (FERNANDES, 2011, p. 9).
\end{abstract}

Com a atenção voltada para o "programa de inserção profissional, denominado Residência Pedagógica, realizado na rede municipal de educação de Niterói no ano de 2011" (COSTA, 2015, p. 9), a pesquisa de Costa discorre acerca do desenvolvimento do profissional docente, pautando-se no objetivo de "investigar o modelo de formação implementado no primeiro ano de estágio probatório para os professores ingressantes" (COSTA, 2015, p. 9) no referido programa. Segundo a autora, seu intuito consiste em refletir "sobre a relevância dos anos iniciais da docência e desenvolvimento profissional docente", destacando "a importância de criarmos espaços compartilhados de formação docente e com ampla participação de todos os envolvidos nas etapas destas formações" (COSTA, 2015, p. 9).

Seguindo uma outra perspectiva, Leite (2015) volta a sua atenção para os professores de Ciências. Fundamentando-se na "Pedagogia da Cooperação" como concepção a ser vivenciada por esses professores, a autora busca, nela, identificar as possibilidades para o ensino das Ciências. De acordo com a autora, seu propósito é "estabelecer um diálogo junto aos professores participantes da Residência Pedagógica, egressos da FFP/UERJ, em duas Oficinas, dentro de uma perspectiva de Desenvolvimento Profissional Docente" (LEITE, 2015, p. 8). Trata-se, portanto, de um estudo que aponta os "espaços de trocas cooperativas, dialógicas e reflexivas das vivências cotidianas da profissão professor" como "possibilidades de novas práticas". Disso, conclui-se que tais espaços "são ambientes ricos de construção de novas possibilidades para a nossa didática em Ciências, tecida de singularidades e particularidades" (LEITE, 2015, p. 8). 


\title{
EIXO 2 - FORMAÇÃO DOCENTE
}

No que se refere à "Formação Docente", estudiosos têm analisado, a partir de dois eixos temáticos, ou seja, da "Formação Inicial" e da "Formação Continuada", visto que estes envolvem etapas distintas do processo de formação docente. Pensando nisso, categorizamos esse eixo como "Formação Docente", de forma que pudesse contemplar as pesquisas que tratam da formação, mas que não as vinculam à "Formação Continuada".

Entre os trabalhos identificados, situamos nesse eixo 08 (oito) deles. São estudos que discorrem acerca das narrativas de professores à luz de estudos do campo dos cotidianos (GAMA, 2014); dos estudantes da FFP/UERJ, em busca de compreender o que os têm levado à escolha do magistério (FERNANDES, 2013); da formação de professoras da(s) infância(s) de um curso normal de Rio Bonito - RJ (FABRICANTE, 2012); do papel do curso de Pedagogia na formação de professoras com experiência no magistério - campus São Gonçalo e Maracanã (BORGES, 2011); do curso de formação de professores, em nível médio, localizado no Bairro do Jardim Catarina - SG (BAROLDI, 2015); das narrativas de professores da Educação Infantil de uma escola de Niterói - RJ (CARPI, 2015); do currículo mínimo do curso normal adotado na rede do Rio de Janeiro (FERNANDES, 2018) e dos processos formativos de professores de Língua Inglesa, egressos da FFP/UERJ, que atuam na Educação de Jovens e Adultos - EJA (MEDEIROS, 2017), conforme destacaremos.

Tomando como base a questão "o que professoras e professores narram sobre seu processo de formação docente" (GAMA, 2014, p. 8), Gama (2014) discorre sobre as narrativas de professores e professoras acerca do trabalho docente. Com um estudo que se debruça sobre a formação inicial, em diálogo com o campo dos cotidianos, a autora recorre às narrativas autobiográficas e, para chegar à sua análise, faz uma discussão a partir do seu próprio memorial de formação, inter-relacionando-o com outros três memoriais. Segundo ela, a escolha metodológica está sustentada em estudiosos do campo que "defendem a escrita do memorial como uma possibilidade de formação" (GAMA, 2014, p. 8)

Para essa pesquisadora,

\begin{abstract}
O que professoras e professores narram sobre seu processo de formação docente? Que interrelações estabelecem entre as experiências docentes cotidianas e o processo de formação? Em que medida os acontecimentos cotidianos são percebidos como experiências formativas? O que enfatizam ou deixam de enfatizar em seus memoriais de formação? (GAMA, 2014, p. 8).
\end{abstract}

Ao final, ela considera que "as reflexões produzidas no diálogo com os memoriais de formação, tendo a própria prática docente como objeto de investigação, confirmam a fertilidade do movimento reflexivo como exercício de (auto) formação" (GAMA, 2014, p. 8).

Dando continuidade, uma pergunta desponta: mas, "afinal, nos dias de hoje, quem quer ser professor ou professora?" Trata-se de uma questão levantada por 
OLIVEIRA, C. C. de $;$ FONTOURA, H. A. da.

Fernandes (2013, p. 8) ao pesquisar as/os estudantes dos cursos de Licenciaturas da FFP/UERJ. Segundo a autora, seu estudo objetiva compreender os motivos que têm levado os estudantes a buscarem os cursos de formação para o exercício do magistério.

Em uma de suas afirmações, destaca:

Apesar da reconhecida importância do papel do profissional professor na construção e no desenvolvimento da sociedade atual, o exercício da docência atravessa um período de grande desprestígio social, refletido, inclusive, na remuneração comumente destinada ao trabalho docente (FERNANDES, 2013, p. 8).

Assim, em busca de respostas sobre "que motivos têm levado estudantes a ingressar em cursos de formação para o exercício do magistério" (FERNANDES, 2013, p. 8), o estudo conclui:

\begin{abstract}
A partir do que foi conhecido, das análises e reflexões construídas, tencionamos contribuir para que a FFP/UERJ tenha novos subsídios à disposição para eventual embasamento da necessária tarefa de permanente atualização de seu Projeto Político-AcadêmicoPedagógico, permitindo-lhe a possibilidade de melhor elaborar seus objetivos e de alcançar suas metas (FERNANDES, 2013, p. 8).
\end{abstract}

Com uma proposta investigativa "fundamentada no diálogo e na participação dos sujeitos (pesquisadora, professoras e normalistas) nela envolvidos" (FABRICANTE, 2012, p. 9), outra autora, Fabricante (2012)

problematiza algumas questões acerca da formação inicial de professoras da(s) infância(s), tendo como contexto de investigação o curso normal em nível médio do Colégio Estadual Desembargador José Augusto Coelho da Rocha Júnior, localizado no município de Rio Bonito (FABRICANTE, 2012, p. 9).

Sua pesquisa "objetivou entender como esta formação vem sendo desenvolvida, partindo da compreensão das concepções pedagógico-curriculares de professoras e estudantes" (FABRICANTE, 2012, p. 9) do curso normal, objeto do seu estudo. Assim, aponta que "o curso normal ainda continua sendo um importante espaço de formação, uma vez que a procura por vagas para turmas de primeiro ano é expressiva" (FABRICANTE, 2012, p. 9).

Segundo a pesquisadora,

No que diz respeito à abordagem do curso sobre a educação infantil, as docentes entendem que a incorporação de disciplinas como Conhecimentos Didáticos Pedagógicos em Educação Infantil e Praticas Pedagógicas e Iniciação à Pesquisa, significaram avanços na/para a formação da professora da infância, uma vez que discutem questões específicas sobre esta etapa da educação básica (FABRICANTE, 2012, p. 9).

Voltando sua discussão para o "papel do Curso de Pedagogia na formação de professoras com experiência no magistério", Borges (2011, p. 8) se propõe a analisar "a 
partir da ótica das professoras, como ocorre a relação de saberes entre a escola e a universidade, através dos processos formativos dessas docentes" (BORGES, 2011, p. 8). Segundo o autor, o seu objeto de estudo é "a circularidade de saberes entre a escola e a universidade" (BORGES, 2011, p. 8), e, em função disso, as análises partiram das informações obtidas na pesquisa com 11 (onze) professoras que realizaram o curso Normal, cursam ou cursaram Pedagogia na UERJ (campus São Gonçalo e Maracanã) e com experiência no magistério (BORGES, 2011)

Em sua análise, o autor buscou "elucidar a relação parental entre o Curso Normal e o Curso de Pedagogia, a relação entre o saber-fazer docente, a relação entre teoria-prática, além de questões relacionadas à identidade profissional, trabalho docente e experiências formativas" (2011, p. 8).

Por fim, aduz que

\begin{abstract}
de acordo com as falas de nossas entrevistadas é possível pensar em uma formação docente que esteja ligada ao dia a dia da escola e em consonância com as exigências da universidade. Sendo assim, à guisa de conclusão desse estudo, podemos entrever que existe uma perspectiva dicotômica no processo de formação docente em que estão colocados de forma polarizada as dimensões dos saberes e fazeres, da teoria e prática, da escola e universidade (BORGES, 2011, p. 8).
\end{abstract}

Já Baroldi (2015, p. 10) procurou investigar "as memórias e histórias da criação do Curso de Formação de Professores em nível médio, do Colégio Estadual Trasilbo Filgueiras, localizado no bairro Jardim Catarina, no município de São Gonçalo". Para tanto, adota como recorte temporal da pesquisa o início da oferta do curso na referida escola, entre os anos de 1984 e 1985. Segundo o pensamento da autora, "a pesquisa justifica-se pela necessidade da reflexão, da rememoração e valorização das memórias escolares e da história da formação de professores no município de São Gonçalo, com vistas ao fortalecimento das instituições públicas que a desenvolvem" (BAROLDI, 2015, p. 10). E, por fim, considera os "sujeitos sociais que cotidianamente, no âmbito da esfera local e global, constroem os processos históricos mediante suas práticas culturais, relações sociais e modos de vida" (BAROLDI, 2015, p. 10).

Ainda no que se refere à formação docente, Carpi $(2015$, p. 8) volta sua atenção para "as narrativas de professores que atuaram no segmento da Educação Infantil do Centro Educacional de Niterói (CEN) ", entre os anos de 1980 e 2006. Sua intenção consiste em "compreender os impactos que a experiência de ser docente no CEN, ou tornar-se doCENte, trouxe para a construção de sua identidade e de sua atuação pedagógica" (CARPI, 2015, p. 8).

Seguindo essa premissa, destaca

a importância da busca pelo conhecimento como elemento constitutivo da identidade docente, ou seja, a formação docente deve ter com preocupação central a formação de professores pesquisadores; a necessidade do estreitamento do diálogo entre escola e universidade; e a transformação de cada escola em centro 
OLIVEIRA, C. C. de $;$ FONTOURA, H. A. da.

de formação docente, em fórum de discussão e construção de saberes e fazeres, em uma perspectiva pessoal e coletiva (CARPI, 2015, p. 8).

Entre os estudos sobre a formação docente, Fernandes $(2018$, p. 8) se volta para a formação inicial visando promover uma discussão a respeito das políticas curriculares, em busca de "analisar o Currículo Mínimo do Curso Normal adotado pela rede estadual do Rio de Janeiro e as bases políticas e epistemológicas presentes no processo que subsidia a proposta" (FERNANDES, 2018, p. 8).

A produção das políticas curriculares traz consigo a disputa de diferentes projetos de formação e de sociedade, entretanto, os sujeitos que dialogam com o currículo proposto irão imprimir a materialidade e o sentido deste documento, ressignificando-o no contexto de sua prática.

A pesquisa em questão teve "como campo o Colégio Estadual Hilka de Araújo Peçanha, instituição de ensino que há trinta e dois anos forma docentes no município de Itaboraí, região metropolitana do estado do Rio de Janeiro" (FERNANDES, 2018, p. 8) e, num âmbito geral, suscita uma "discussão acerca dos impactos das lógicas gerenciais no campo das políticas de formação docente, assim como nas políticas curriculares" (FERNANDES, 2018, p. 8). Em suma, apreende-se, a partir do estudo, "que o Curso Normal ainda permanece sendo um importante lócus de formação, visto que grande quantitativo de professores atuantes na Educação Infantil e nos anos iniciais do Ensino Fundamental possui esta formação inicial"(2018, p. 8).

Por fim, problematizando os desdobramentos da formação de professores de Língua Inglesa, Medeiros (2017, p. 10) assevera que "os processos formativos de professores de Língua Inglesa começam muito antes da entrada na universidade e se estendem ao longo de toda a profissão". Nesse sentido, propõe uma reflexão sobre

A formação profissional de seis docentes de Inglês ao delinear o perfil acadêmico desses professores, egressos da Faculdade de Formação de Professores, da Universidade do Estado do Rio de Janeiro (FFP/UERJ) que atuam na Educação de Jovens e Adultos (EJA), além de clarificar os principais desafios que esses docentes enfrentam no cotidiano da sala de aula da EJA (MEDEIROS, 2017, p. 10).

Fundamentando a sua opção teórico-metodológica, destaca o seu desejo de "trazer à tona a necessidade de se respeitar a bagagem cultural do público da EJA na formação do currículo de Inglês desenvolvido nas escolas" (MEDEIROS, 2017, p. 10), trabalhando o ensino numa perspectiva dialógica.

Os processos formativos dos participantes desta pesquisa e os desafios de ensinar Inglês para essa modalidade. Esta pesquisa mostrou a urgência da inserção do tema Educação de Jovens e Adultos na formação de professores, a importância do desenvolvimento profissional docente que vai muito além de cursos 
formais, além de apresentar alguns desafios de ensinar Inglês para essa modalidade de ensino (MEDEIROS, 2017, p. 10).

Diante do exposto, podemos considerar que os estudos em debate ressaltam o importante papel exercido pelas escolas de formação de professores em nível médio (escola Normal), sobretudo no trabalho com a(s) infância(s). Acentuam o papel da FFP/UERJ na formação de professoras/es, promovem uma discussão acerca do currículo das escolas normais, problematizam a formação dos professores de Inglês e trabalham a formação, tomando como base as narrativas das professoras, apresentando diálogos com o campo dos cotidianos.

\title{
EIXO 3 - FORMAÇÃO CONTINUADA
}

Quanto à "Formação Continuada", foram identificados 05 (cinco) trabalhos: Silva (2018) estuda a formação de professoras das Infâncias da Creche da Universidade Federal Fluminense - UFF; Figueira (2012) discute o tema a partir dos olhares e vozes docentes de professoras do primeiro ciclo do ensino fundamental; Gnisci (2012) aborda a questão dos professores - Incentivadores de Leitura - na educação (em tempo) integral; Oliveira (2012), pautada nos estudos do campo dos cotidianos, trabalha com professoras que atuam nas séries iniciais do ensino fundamental de uma escola da rede municipal de São Gonçalo - RJ e Bianchini (2016), com estudo em torno das narrativas docentes e das rodas de conversa, investiga os possíveis caminhos para a formação docente em uma escola localizada em Colubandê - SG.

Para Silva (2018, p. 8), o objetivo do seu trabalho consiste em "estudar a importância do registro docente na formação continuada das professoras das Infâncias", a partir de experiências na Creche da Universidade Federal Fluminense. Trata-se de um estudo de cunho autobiográfico, que discute, à luz do "cotidianos", os saberesfazeres, "suas múltiplas e complexas relações, é o que compõe um cotidiano de conhecimentos e significações que se tecem nos espaçostempos da escola" (SILVA, 2018, p. 8).

Ao final, reafirma

\begin{abstract}
a importância de toda professora se colocar como pesquisadora da própria prática. A formação inicial ou continuada no e com o cotidiano potencializa a professora das infâncias, que passa a ter a investigação, o registro e a socialização como ferramentas essenciais para compreender suas ações e produzir conhecimentos com maior autonomia (SILVA, 2018, p. 8).
\end{abstract}

Em busca de "compreender a formação continuada através dos olhares e vozes docentes" (FIQUEIRA, 2012, p. 7), Figueira (2012) procurou identificar "as mobilizações efetuadas por três professoras do primeiro segmento do ensino fundamental na busca por formação" (FIQUEIRA, 2012, p. 7). Ele defende que "interrogar a si constitui-se uma dinâmica provocadora que proporciona o acesso a conhecimentos agregados durante a trajetória formativa e produtora de intervenções positivas na ação cotidiana docente" (FIQUEIRA, 2012, p. 7). Do ponto de vista metodológico, a investigação inscreve-se na 
"pesquisa-formação" e traz como consideração "a necessidade de se compreender o desenvolvimento pessoal e profissional do professor atrelado às experiências cotidianas" (FIGUEIRA, 2012, p. 7).

Situando-se em um recorte mais específico, Gnisci (2012) volta a sua pesquisa para professores - Incentivadores de Leitura - na educação (em tempo) integral. Assim, a autora discute acerca da formação institucional do professor e os desafios enfrentados por ele, sendo este atuante nesse segmento da educação. De acordo com a pesquisa, o seu objetivo principal consiste em "analisar as implicações - repercussões e tendências do processo de Formação Continuada do Programa Bairro-Escola para Incentivadores da Leitura e sua contribuição para a Educação Integral no Município de Nova Iguaçu" (GNISCl, 2012, p. 8).

Essa autora evidencia, ainda, que a leitura, enquanto manifestação literária e campo de conhecimento, constitui parte da formação integral dos indivíduos, exercendo influência nos vários espaços/tempos de formação do aluno e do professor. Para ela, os saberes relacionados à leitura constituem preceitos de programas precursores - como os CIEPs e Escola-Parque - e modelos atuais, como o Bairro-Escola. Ao final, constata "a efetividade da Formação Continuada, com pequenas inferências por parte dos professores participantes" e aponta "fragilidades e entraves, dentre eles, ausências de referências do Incentivador da Leitura" (GNISCI, 2012, p. 8).

Com uma discussão fundamentada no "cotidiano escolar", Oliveira (2012, p. 9) inicia o seu estudo destacando que a "temática da formação contínua de professores/as tem sido recorrente não apenas nos debates e estudos produzidos no âmbito educativo, mas, sobretudo, no aumento considerável de propostas instituídas em nível nacional e internacional". Segundo a autora, o seu estudo buscou compreender como os/as professores/as vivem a tensão entre o instituído e instituinte que atravessa o cotidiano da escola e ainda" e "que implicações essa partilha de experiências pode trazer para o seu processo de (trans) formação docente" (OLIVEIRA, 2012, p. 9). Quanto aos sujeitos, a pesquisa se dá com "professoras que atuam nas séries iniciais do ensino fundamental de uma escola municipal da rede de São Gonçalo" (OLIVEIRA, 2012, p. 9).

Em suma, a pesquisa de Oliveira conclui que há uma

relação indissociável e de extrema complexidade que envolve o diálogo entre o instituído e instituinte na escola, bem como a necessidade de atentarmos para as condições de trabalho dos/as professores/as e para as diversas temporalidades de sua formação docente, que não se limitam aos tempos instituídos de formação, mas, vão ao encontro de outros sincronizadores de tempo, considerando os sentidos e usos da formação sob a ótica docente (2012, p. 9).

Já a pesquisa desenvolvida por Bianchini (2016) nos incita a pensar na formação contínua do profissional docente ao apontar que "a formação docente tem sido objeto de muitos estudos de pesquisadores na área da educação, entretanto, tem tido pouco efeito na vida profissional dos professores" (BIANCHINI, 2016, p. 6). A autora aponta, ainda, que a pesquisa desenvolvida vislumbra "pensar em uma formação fundamentada na profissão, que traga significado para o dia a dia desses profissionais" (BIANCHINI, 2016, p. 6). Assim, ela define o seu objetivo, através do qual busca "analisar as possíveis 
contribuições formativas do compartilhamento de experiências sobre a prática pedagógica entre professores do Colégio Estadual Doutor Rodolpho Siqueira, localizado no Colubandê, São Gonçalo, Rio de Janeiro" (BIANCHINI, 2016, p. 6). Por fim, Bianchini (2016, p. 6) aponta que o "estudo trouxe como contribuições o reconhecimento da escola como local possível para dar continuidade à formação, bem como a importância e a potência da roda de conversa e do estudo das narrativas para a formação de professores".

Com base nos estudos apresentados, foi possível notar o uso das narrativas de professores nas discussões acerca da "Formação Continuada", bem como a sua relação com estudos do campo dos cotidianos. Assim, depreende-se por trabalhar a formação a partir da prática docente, explorando as experiências que dão sentido ao seu quefazer pedagógico. Desse modo, a prática passa ser o local de partida e de chegada para o professor, no seu constante fazer-se pesquisador.

\section{EIXO 4 - DOCÊNCIA UNIVERSITÁRIA}

Entre os estudos realizados, identificamos apenas um estudo voltado para a "Docência Universitária". Por meio dele, notamos que o autor apresenta a universidade como "uma instituição social historicamente integrada em relações de poder" (PINA, 2013, p. 7), na qual o professor universitário é "uma figura central na articulação dessas relações" (PINA, 2013, p. 7). Acrescenta, ainda, que "o processo de formação desse professor se estabeleceu tradicionalmente no princípio do domínio dos conteúdos cognitivos e aprimoramento científico, com descaso pela preparação pedagógicodidática" (PINA, 2013, p. 7). Utilizando-se de uma abordagem crítico dialética, Pina (2013) desenvolve o seu trabalho com sujeitos, professores da Faculdade de Formação de Professores da Universidade do Estado do Rio de Janeiro - UERJ/FFP.

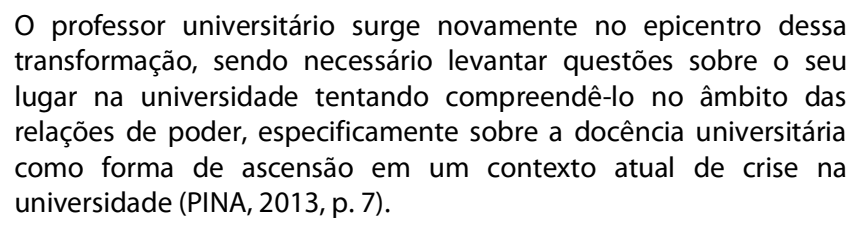
transformação, sendo necessário levantar questões sobre o seu lugar na universidade tentando compreendê-lo no âmbito das relações de poder, especificamente sobre a docência universitária como forma de ascensão em um contexto atual de crise na universidade (PINA, 2013, p. 7).

A partir do trabalho desenvolvido por Pina (2013), podemos destacar que a relações constituídas no âmbito da Pós-Graduação são extremamente importantes, tendo em vista que oferecem elementos teóricos, troca de saberes, que resultam na/da problematização da prática, contribuindo, assim, para a formação. Além disso, possibilitam uma maior aproximação entre esta e a graduação.

\section{DA RELAÇÃO PESQUISADOR/ORIENTADOR}

Diante dos estudos analisados, no primeiro momento, percebemos a presença do professor como investigador de sua prática (KINPARA, 2015), tendo em vista que as pesquisas derivam de um processo reflexivo, a partir da articulação entre a teoria e a 
prática. Nesse sentido, o processo de construção do conhecimento se dá a partir da problematização dessa prática, resultando num "contínuo processo de aprendizagem, desaprendizagem, reaprendizagem" (CANDAU, 2018, p. 6).

Num segundo momento, a investigação assume um papel importante na formação, uma vez que - à luz da práxis - suscita nova discussões teóricas, sobretudo a partir da relação dialógica construída com o/a orientador/a. Nóvoa (2020) nos lembra da importância dos professores, das relações tecidas por eles, tanto no que se refere à formação, como na busca por respostas para as questões da educação. Logo, a relação entre o/a pesquisador/a e o/a orientador/a é fundamental para que se construa um espaço de cooperação, pois trata-se de uma aprendizagem coletiva.

Tardif e Lessard (2009, p. 31) afirmam que "ensinar é trabalhar com seres humanos, sobre seres humanos, para seres humanos". Uma premissa que, no nosso entendimento, pode ser associada também à pesquisa, tendo em vista os seus sujeitos e as contribuições que ela trará para estes e para as comunidades local e acadêmica. Os autores destacam, ainda, que a "docência é um trabalho cujo objeto é constituído de relações humanas" (TARDIF; LESSARD, 2009, p. 35) com e por pessoas. Assim, para além da relação pesquisador/orientador, estamos falando da relação entre professores, do ponto de vista da experiência e da profissão que exercem; mas também de uma relação "docente-discente", como nos lembra Freire (1996; 1997). Sobre esse assunto, recorremos às suas palavras para ressaltar a importância "de falar ao educando a falar a ele e com ele; de ouvir o educando a ser ouvido por ele" (FREIRE, 1997, p. 58), ou seja, da construção de um espaço dialógico, de cooperação entre pesquisador/orientador, de forma que a pesquisa resulte em um espaço de construção do pensamento crítico, trazendo contribuições para (re)pensar ação docente.

Afinal, como bem afirmou Nóvoa (2020, n.p.), "os professores têm um papel importante na escola e na sociedade", além de ampliar essa ideia ao destacar que "as profissões do humano estão relacionadas a uma ética humana da ação" (NÓVOA, 2020, n.p.). Acerca desse assunto, Freire (1996) também nos chama a atenção ao falar da "relação ética" na relação educador/educando. Desse modo, as questões éticas condições necessárias à prática - estão, também, entrelaçadas à ação da pesquisa, tanto no que se refere aos dados e informações, como nas relações com os sujeitos pesquisados e entre estes e os sujeitos responsáveis pela pesquisa, ou seja, pesquisador/a e orientador/a.

Acerca da relação entre as/os pesquisadoras/es e suas orientadoras, utilizamos aqui o termo no feminino porque, das dezessete dissertações analisadas, todas foram orientadas por professoras. Dessas, 09 (nove) foram orientados pela Prof. ${ }^{a}$ Helena Amaral da Fontoura; 03 (três) pela Prof. a Jacqueline de Fátima dos Santos Morais; 02 (duas) pela Prof.a Inês Ferreira de Souza Bragança; 01 (uma) pela Prof. ${ }^{a}$ Maria Tereza Goudard Tavares; 01 (uma) pela Prof. a Lúcia Veloso Maurício; e 01 (uma) pela Prof. ${ }^{a}$ Mairce da Silva Araújo. Assim, por meio da articulação teórico-prática feita pelas/os pesquisadores, podemos perceber o compromisso ético da pesquisa, especialmente por levar em consideração a sua "Formação Inicial" ao trazer para discussão o trabalho escolar e as questões do cotidiano.

As problemáticas discutidas pelas/os pesquisadoras/es, no decorrer de sua pesquisa, resultaram de narrativas, histórias e memórias, de rodas de conversa, da relação entre a escola e a universidade; de residência pedagógica, currículo para a 
formação docente e docência universitária; remetendo a Freire (2007), são "quefazeres" que levam em consideração a experiência concreta dos sujeitos que pesquisam e que ao pesquisar partem dessa realidade, superando a dicotomia entre a teoria e a prática.

Freire (2007, p. 59) destaca que "um dos obstáculos à nossa prática está em ir às áreas populares com nossos esquemas "teóricos" ${ }^{16}$ montados e não nos preocupamos com o que as pessoas sabem, os indivíduos que lá estão, e como sabem". Um obstáculo que, por meio das pesquisas analisadas, parece ter sido superado, não somente por levar em consideração as situações do cotidiano, mas pelo emprego de vocábulos como escuta, diálogo, conversa, roda de conversa", algo que nos remete a Freire e Guimarães (2011), pois, à medida que problematizamos a nossa própria história, com ela, vamos aprendendo e (re)inventando a nossa prática.

Por fim, destacamos que a prática educativa "é uma dimensão necessária da prática social" (FREIRE, 2007, p. 68) que "implica em opções, rupturas, decisões" (FREIRE, 2007 , p. 43). Assim, o ato de refletir sobre a nossa prática, no âmbito da pesquisa, sugere uma abertura para outras formas de ação a partir dessa relação com os sujeitos e do conhecimento de novas epistemologias. Nesse sentido, a pesquisa resulta em um processo interativo, relacional e dialógico, através do qual vamos nos formando. Um processo dinâmico em que "a prática precisa da teoria como a teoria precisa da prática" (FREIRE, 2007, p. 88), resultando em um conhecimento que se dá na ação e a partir da reflexão na/sobre ela (SCHON, 1992).

\section{ALGUMAS CONSIDERAÇÕES}

O estudo em questão, além suscitar uma discussão acerca da "Formação de Professores", reforça a importância dele como campo de estudo ao compilar e analisar pesquisas realizadas no âmbito da pós-graduação, sobretudo na conjuntura atual em que a Pós-graduação tem sido alvo de ataques, de cortes de verbas. Diante disso, ele nos deixa uma lição acerca/sobre a potência das "vozes" quando se unem em defesa de uma causa, no caso em tela, acerca da educação. Por outro lado, acentua o compromisso do Programa de Pós-Graduação em Educação da Faculdade de Formação de Professores, da Universidade do Estado do Rio de Janeiro, com o campo da "Formação de Professores", uma vez que este se apresenta como eixo temático de uma das suas linhas de pesquisa. Algo possível de ser notado ao considerarmos que, dos 178 estudos, ou melhor, das dissertações de mestrado realizadas no PPGEdu, 17 delas dão enfoque à "Formação de Professores", ou seja, têm-na como objeto de estudo. Isso significa dizer que praticamente $10 \%$ das pesquisas estão voltadas para o estudo dessa temática. Nesse sentido, concluímos que o PPGEdu, ao longo de sua existência, vem exercendo um papel fundamental nas discussões acerca da educação de São Gonçalo e Adjacências.

Por meio da análise, notou-se que as pesquisas realizadas por estudantes do programa refletem a sua inserção local ao trazer experiências e práticas do cotidiano para serem discutidas, resultando num movimento que tem suscitado em outras formas de pensar e fazer educação, visto que há uma articulação teórico-prática capaz de levar aquelas/es pesquisadoras/es a conhecer e buscar novas formas de ação. Acentuamos, ainda, que a formação das/os estudantes tem se dado a partir das relações tecidas entre 
os diversos sujeitos, uma vez que o seu público é formado por professoras/es, havendo uma predominância do público feminino: entre $80 \%$ e $90 \%$.

Notadamente, são pesquisadoras que discutem o local, o território em que se dão suas práticas, suscitando debates sobre a formação e atuação de professores nos municípios de São Gonçalo, Itaboraí, Niterói, Rio Bonito, Rio de Janeiro e Nova Iguaçu. Pensando assim, ao destacarmos o compromisso do PPGEdu com as questões locais, ressaltamos sua relevância social, tendo em vista que, seja por meio dos professores do programa que em seus grupos de pesquisa problematizam, dialogam, sobre as realidades estudadas, seja pelos próprios pesquisadores que, ao pesquisar, passam a olhar e compreender a realidade de forma mais crítica.

Diante disso, concordamos com Marcondes e Flores que

\begin{abstract}
a formação de professores tem sido objeto de investigação e de atenção por parte de acadêmicos, decisores políticos, formadores e investigadores no sentido de promover a sua qualidade e de potenciar a sua eficácia em termos de desenvolvimento de competências e de conhecimentos necessários para o exercício da função docente (2014, p. 298).
\end{abstract}

O pensamento dessas autoras nos traz alguns elementos considerados importantes para esta discussão. O primeiro diz respeito à "formação de professores como objeto de investigação", pois encontra sentido nas pesquisas realizadas no âmbito do PPGEdu, nas quais as/os discentes, ao pesquisar, fazem uma discussão a partir de sua prática, da sua experiência. Nesse sentido, o processo que envolve a pesquisa se torna, também, um ato político, pois envolve escolhas, caminhos, perspectivas de fazer pesquisa e aprender com ela. O segundo refere-se aos "interessados por este objeto". Além de acadêmicos, formadores e investigadores, as autoras nos falam dos "decisores políticos", entendido aqui como aqueles que pensam, que estão à frente das políticas públicas, sobretudo nas tomadas de decisões. Nessa direção, o campo da "Formação de Professores" torna-se, ao mesmo tempo, um campo de convergências e disputas. Converge, no sentido de que o seu objetivo é formar professores, contribuindo para desenvolvimento das competências necessárias para a sua função; e de disputas, quando se refere, sobretudo, ao projeto político: a serviço de qual modelo de educação, de quais políticas, a formação está? Por fim, pensando na formação de professores no PPGEdu, as pesquisas analisadas nos apontam uma resposta: o programa defende uma formação que reconhece o papel dos múltiplos e diversos sujeitos e/em seus processos formativos, fazendo uma discussão entrelaçada pelas questões das desigualdades sociais. Afinal, são desigualdades que atravessam a escola e, portanto, a prática docente.

Pensando assim, a nossa análise considera que tanto as questões de pesquisa como os objetos de estudo têm como ponto de chegada ou como ponto de partida (MARCONDES, 2004) a prática docente, o cotidiano da escola, histórias, memórias, diálogos entre professores, encontros, políticas de formação. São, portanto, discussões que possibilitam - em seu fazer - um movimento entre a ação de pesquisar, as reflexões por ela suscitadas, ou seja, são ações sistematizadas entre si, que articulam a discussão teórica aos elementos da prática, tanto da prática da pesquisa como da própria prática, visto que assumem o seu papel de professora-pesquisadora. 
Notamos, ainda, a presença de alguns estudos que discutem a "Formação Inicial" de Professores na FFP, na UERJ e na UFF, levantando questões sobre o porquê da escolha de ser professor, a residência pedagógica, a inserção profissional e a relação entre a escola e a universidade. A partir deles, acentuamos a correlação entre as temáticas abordadas, ou seja, as "vozes" em diálogo, uma vez que discutem o processo formativo desde a escolha pelos cursos de licenciaturas até a compreensão dos desafios enfrentados na inserção profissional. No que se refere à relação entre a escola e a universidade, acreditamos que a residência pedagógica, os projetos de extensão e as próprias pesquisas, ao discutirem temáticas referentes ao cotidiano da escola, ao suscitarem diálogos entre pesquisadoras/es e orientadores/as, aproximam esses dois espaços fundamentais para a "Formação de Professores".

Por fim, compreendemos que, seja por meio das narrativas (auto)biográficas, pelas discussões do campo dos cotidianos, pela historicização ou observação de campo, as pesquisas realizadas nos sugerem que o PPGEdu compreende a "Formação de Professores" como uma ação política. Afinal, a qualificação de professores é uma das premissas básicas para a melhoria da qualidade da educação, fortalecendo o trabalho e a luta contra as desigualdades sociais.

Acreditamos, portanto, que a polifonia de vozes - ao longo deste estudo trouxe elementos para pensarmos a "Formação de Professores" ao demonstrar, sob diferentes perspectivas, que as pesquisadoras discutem a temática relacionando elementos teórico-metodológicos com o seu olhar reflexivo sobre o local. Sendo assim, a pesquisa é resultado da problematização, descrição e análise da realidade que, por ser familiar, lhe desperta interesse, levando a buscar outras formas de ação.

Em suma, este estudo evidencia o compromisso do PPGEdu (FFP/UERJ) com o campo da "Formação de Professores", inclusive pela inter-relação entre as suas duas linhas de pesquisa, ou seja, entre "Formação de Professores" e "Políticas". Um compromisso que, na visão Freire (2018), está relacionado ao fato de debruçar-se sobre a realidade, problematizando-a em diálogo com outras vozes, com estudiosos do campo. Esse autor nos lembra que "na reflexão sobre a ação, na observação atenta a outras práticas ou à prática de outros sujeitos, na leitura persistente, crítica de outros teóricos" (FREIRE, 2007, p. 89), tornando-nos professores e compreendendo a educação, bem como as escolhas da pesquisa, como um compromisso político.

Assim, ao levar em consideração os contextos locais e a realidade da/os pesquisadoras/es, as pesquisas, bem como os seus resultados, reforçam o papel político, tanto da formação quanto da pesquisa, contribuindo para que tenhamos professoras/es críticas/os que trabalhem em prol de uma educação pública, gratuita e de qualidade, comprometida com a redução das desigualdades sociais.

Artigo recebido em: 20/08/2020

Aprovado para publicação em: 17/11/2020 
OLIVEIRA, C. C. de; FONTOURA, H. A. da.

STUDIES ON TRAINING TEACHER PERFORMED IN MASTERS EDUCATION AT FFP / UERJ: WHAT ARE THE CONTRIBUTIONS?

ABSTRACT: The present study aims to raise dialogues about teacher education, taking as reference the researches carried out by students of the Master's degree in Education Formative Processes and Social Inequalities of the Faculty of Teacher Training of the State University of Rio de Janeiro - FFP/UERJ. Through a bibliographic survey, we seek to reflect on the discussions held by students of the program - between the years 2010 and 2018 - recognizing the power of a "what to do" (FREIRE, 1987; 2007) that involves not only the action of researching and reflecting on teaching practice, but a new action that consists of (re)thinking the process resulting from the research, that is, learning "in it and with it". In this sense, the questions raised here in dialogue with Nóvoa (1992; 1995) and Freire (1996; 1997), intend to contribute theoretically and methodologically to the field of Teacher Education, based on the following axes: insertion of the teaching professional, development of the teaching professional, Initial Training, Continuing Education and University Teaching.

KEYWORDS: Teacher Training. Teacher-researcher. Teaching Practice. Dialog. Politics.

ESTUDIOS EN FORMACIÓN DOCENTE REALIZADOS EN EL MÁSTER EN EDUCACIÓN FFP / UERJ: ¿CUÁLES SUS CONTRIBUCIONES?

RESUMEN: El estudio en cuestión tiene como objetivo plantear diálogos sobre la educación del profesorado, tomando como referencia la investigación realizada por los alumnos del Máster en Procesos Formativos Educativos y Desigualdades Sociales de la Facultad de Formación del Profesorado de la Universidad Estatal de Río de Janeiro - FFP/UERJ. A través de la encuesta bibliográfica, tratamos de centrarnos en las discusiones realizadas por los estudiantes del programa - entre 2010 y 2018 - reconociendo el poder de un "hacer" (FREIRE, 1987; 2007) que implica no sólo la acción de investigar y reflexionar sobre la práctica docente, sino una nueva acción que consiste en (re)pensar a partir del proceso resultante de la investigación, es decir, aprender "en ella y con ella". En este sentido, las cuestiones planteadas aquí en diálogo con estudiosos como Nóvoa $(1992 ; 1995)$ y Freire $(1996 ; 1997)$ pretenden contribuir teórica y metodológicamente al campo de la Educación del Profesorado, basado en los siguientes ejes: inserción del profesional docente, desarrollo del profesional docente, Educación Inicial, Educación Continua y Enseñanza Universitaria.

PALABRAS CLAVE: Formación del Profesorado. Profesor-investigador. Práctica Docente. Diálogo. Política.

\section{NOTAS}

1 - Essa informação leva em consideração os estudantes matriculados em 2017, embora os estudos analisados sejam somente de alunos matriculados entre 2009 e 2016.

2 - Em função do prazo de até 24 meses para concluir mestrado, ressaltamos que, embora a primeira turma tenha iniciado em 2009, os estudos só foram concluídos a partir de 2010. 
3 - "O estado da arte é um mapa que nos permite continuar caminhando. É também uma possibilidade de suscitar discursos que à primeira vista podem parecer como descontínuos e contraditórios. No estado da arte há a possibilidade de contribuir com a teoria e com a prática de algo, neste caso com a formação docente" [Tradução nossa].

4 - Os textos analisados encontram-se disponíveis no site do programa: https://ppgedu.org/ffp/teses.html.

5 - Grifos da autora em referência a ALVES, Nilda. A compreensão de políticas nas pesquisas com os cotidianos para além dos processos de regulamentação. Educação e Sociedade, Campinas, v. 31, n.113, p. 1195-1212, dez. 2010.

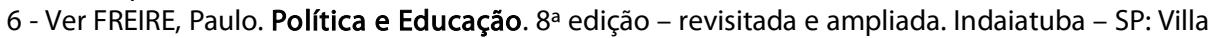
das Letras, 2007.

\section{REFERÊNCIAS BIBLIOGRÁFICAS}

ANDRE, Marli. Formação de professores: A constituição de um campo de estudos. Educação, Porto Alegre, v. 33, n. 3, p. 174-181, set./dez. 2010.

BAROLDI, Karyne Alves. Por entre histórias e memórias: caminhos do curso de formação de professores do Colégio Estadual Trasilbo Filgueiras (1984-1985). 2015. 186f. Dissertação (Mestrado em Processos Formativos e Desigualdades Sociais) - Faculdade de Formação de Professores de São Gonçalo, Universidade do Estado do Rio de Janeiro, São Gonçalo, 2015.

BIANCHINI, Flávia Renata Silva Jorio. Encontros de formação através da roda de conversa entre professores do Colégio Estadual Doutor Rodolpho Siqueira, Colubandê, São Gonçalo/RJ. 2016. 103f. Dissertação (Mestrado em Educação) Faculdade de Formação de Professores, Universidade do Estado do Rio de Janeiro, São Gonçalo, 2016.

BORGES, Luís Paulo Cruz. Tecendo diálogos \& construindo pontes: a formação docente entre a escola e a universidade. 2011. 132f. Dissertação (Mestrado em Processos Formativos e Desigualdades Sociais) - Faculdade de Formação de Professores de São Gonçalo, Universidade do Estado do Rio de Janeiro, São Gonçalo, 2011.

VOSGERAU, Dilmeire Sant'Anna Ramos; ROMANOWSKI, Joana Paulin. Estudos de revisão: implicações conceituais e metodológicas. Rev. Diálogo Educ., Curitiba, v. 14, n. 41, p. 165-189, jan./abr. 2014. Disponível em: https://periodicos.pucpr.br/index.php/dialogoeducacional/article/view/2317 Acesso: 18 nov. 2020.

CANDAU, Vera Maria. Prefácio. In: OLIVEIRA, Ivanilde Apoluceno de; SANTOS, Tânia Regina Lobato dos. MARCONDES, Maria Inês (Orgs.) A Educação de Paulo Freire nos contextos Latino e Norte-Americanos. Belém-Pará: CCSE-UEPA, 2016, p. 6-8. 
OLIVEIRA, C. C. de; FONTOURA, H. A. da.

CARPI, Ana Cristina Menegaz dos Santos. Tornar-se doCENte: uma viagem pelas experiências formativas de professores da Educação Infantil do Centro Educacional de Niterói de 1980 a 2006. 2014. 220f. Dissertação (Mestrado em Processos Formativos e Desigualdades Sociais) - Faculdade de Formação de Professores de São Gonçalo, Universidade do Estado do Rio de Janeiro, São Gonçalo, 2014.

COSTA, Luciana Laureano. Residência Pedagógica: criando caminhos para o desenvolvimento profissional docente. 2015. 128f. Dissertação (Mestrado em Educação) - Faculdade de Formação de Professores, Universidade do Estado do Rio de Janeiro, São Gonçalo, 2015.

FABRICANTE, Bruna de Souza. Investigando caminhos formativos de professoras da(s) infância(s) em Rio Bonito: o curso normal em questão. 2012. 180f. Dissertação (Mestrado em Processos Formativos e Desigualdades Sociais) - Faculdade de Formação de Professores de São Gonçalo, Universidade do Estado do Rio de Janeiro, São Gonçalo, 2012.

FERNANDES, Flavia da Conceição Ramos. Políticas curriculares para o curso Normal na rede estadual do Rio de Janeiro: o currículo mínimo e suas implicações para a formação docente. 2018. 122f. Dissertação (Mestrado em Processos Formativos e Desigualdades Sociais) - Faculdade de Formação de Professores de São Gonçalo, Universidade do Estado do Rio de Janeiro, São Gonçalo, 2018.

FERNANDES, Gláucia Braga Ladeira. Universidade e inserção profissional: um estudo de egressos das Licenciaturas da Faculdade de Formação de Professores da UERJ. 2011. 147f. Dissertação (Mestrado em Educação) - Faculdade de Formação de Professores, Universidade do Estado do Rio de Janeiro, São Gonçalo, 2011.

FERNANDES, Neiva Santos Masson. Quem quer ser professor ou professora? Um estudo com graduandos dos cursos de licenciatura da Faculdade de Formação de Professores da UERJ. 2013. 221f. Dissertação (Mestrado em Educação) - Faculdade de Formação de Professores, Universidade do Estado do Rio de Janeiro, São Gonçalo, 2013.

FIGUEIRA, Sandro Tiago da Silva. Os contextos e movimentos na formação continuada docente: uma busca de sentido. 2012. 106f. Dissertação (Mestrado em Processos Formativos e Desigualdades Sociais) - Faculdade de Formação de Professores de São Gonçalo, Universidade do Estado do Rio de Janeiro, São Gonçalo, 2012.

FREIRE, Paulo. Educação e Mudança. 38 ed. Rio de Janeiro/São Paulo: Paz e Terra, 2018.

FREIRE, Paulo. Pedagogia da autonomia: saberes necessários à prática educativa. São Paulo: Paz e Terra, 1996.

FREIRE, Paulo. Pedagogia do Oprimido. 17. ed. Rio de Janeiro, Paz e Terra, 1987.

FREIRE, Paulo. Política e Educação. 8a Edição - revisada e ampliada. Indaiatuba, SP - Vila da Letras, 2007.

Inter-Ação, Goiânia, v.46, n.1, p. 216-237, jan./mar. 2021. Disponível em: <http://dx.doi.org/10.5216/ia.v45i3.65164>. 
FREIRE, Paulo. Professora sim, tia não. São Paulo: Olho d'Água, 1997.

FREIRE, Paulo; GUIMARÃES, Sérgio. Aprendendo com a própria história. São Paulo: Paz e Terra, 2011.

GAMA, Daniele de Almeida. O que narram professores e professoras sobre seu processo de formação docente? Da formação inicial às experiências cotidianas. 2014. 107f. Dissertação (Mestrado em Educação) - Faculdade de Formação de Professores, Universidade do Estado do Rio de Janeiro, São Gonçalo, 2014.

GNISCl, Vanessa Monteiro Ramos. Processos Formativos do Incentivador da Leitura em Nova Iguaçu: Experiências de Educação (em tempo) Integral. 2012. 135f. Dissertação (Mestrado em Processos Formativos e Desigualdades Sociais) - Faculdade de Formação de Professores de São Gonçalo, Universidade do Estado do Rio de Janeiro, São Gonçalo, 2012.

KINPARA, Minoru Martins. A formação do professor por meio da prática reflexiva. Boletim GEPED - UFAC, Brasil, Edição n 03, out./2015, n.p.

LEITE, Claudia Almada. Diálogos formativos entre Pedagogia da Cooperação, Desenvolvimento Profissional Docente e ensino de Ciências. 2015. 173f. Dissertação (Mestrado em Educação) - Faculdade de Formação de Professores, Universidade do Estado do Rio de Janeiro, São Gonçalo, 2015.

MARCONDES, Maria Inês. Prática Reflexiva: ponto de chegada ou ponto de partida na Formação do Professor. In: BARBOSA, Raquel Lazzari Leite. (Org.). Trajetórias e Perspectivas da Formação dos Professores. 1. ed. São Paulo: Editora UNESP, 2004, v. 1, p. 197-210.

MARCONDES, Maria Inês; FLORES, M. A. O auto estudo e as abordagens narrativobiográficas na formação dos professores. Educação (PUCRS. Impresso), Rio Grande do Sul, v. 37, p. 297-306, 2014.

MEDEIROS, Letícia Miranda. Processos formativos de docentes de inglês que trabalham na educação de jovens e adultos: estudo com egressos da Faculdade de Formação de Professores da Universidade do Estado do Rio de Janeiro. 2017. 116 f. Dissertação (Mestrado em Educação) - Faculdade de Formação de Professores, Universidade do Estado do Rio de Janeiro, São Gonçalo, 2017.

MESSINA, Graciela. Investigación en o investigación acerca de la formación docente: un estado del arte en los noventa. Revista Iberoamericana de Educación, Espanha, n. 19 (1999), págs. 145-207. Disponível em: https://rieoei.org/historico/oeivirt/rie19a04.PDF Acesso: 18 nov. 2020. 
OLIVEIRA, C. C. de; FONTOURA, H. A. da.

NÓVOA, A. Formação de professores e profissão docente. In: NÓVOA, A. (Org.). Os professores e a sua formação. Lisboa: Don Quixote, 1995.

NÓVOA, A. Formação de professores em tempos de pandemia. In: Webconferência realizada pelo Instituto lungo, em 23 jun. 2020. Disponível em: https://www.youtube.com/watch?v=ef3YQcbERiM. Acesso: 23 jun. 2020.

NÓVOA, A. (org.). Vidas de Professores. Porto: Porto Editora, 1992.

OLIVEIRA, Mariza Soares de. Entre os movimentos instituídos e instuintes de formação docente: tensões do/no cotidiano escolar. 2012. 200f. Dissertação (Mestrado em Processos Formativos e Desigualdades Sociais) - Faculdade de Formação de Professores de São Gonçalo, Universidade do Estado do Rio de Janeiro, São Gonçalo, 2012.

PINA, Ricardo Miguel da Conceição. A docência universitária como estratégia de ascensão: um estudo com a Faculdade de Formação de Professores da Universidade do Estado do Rio de Janeiro. 2013. 150f. Dissertação (Mestrado em Educação - Processos Formativos e Desigualdades Sociais) - Faculdade de Formação de Professores, Universidade do Estado do Rio de Janeiro, São Gonçalo, 2013.

PPGEdu. Linhas de pesquisa. Disponível em: https://ppgedu.org/ffp/Linhas.html Acesso: 20 jul. 2019.

PPGEdu. Estrutura do programa. Disponível em: https://ppgedu.org/ffp/estrutura.html . Acesso: 20 jul. 2019.

SCHOM. Donald A. La formación de profesionales reflexivos. Buenos Aires-BarcelonaMéxico, Ediciones Paidós, 1992.

SILVA, Tatiane Nogueira da. Escrever, refletir, compartilhar: marcas da formação continuada em registros de uma professora das infâncias. 2018. 100f. Dissertação (Mestrado) - Faculdade de Formação de Professores, Universidade do Estado do Rio de Janeiro, São Gonçalo, 2018.

TARDIF, Maurice; LESSARD, Claude. O trabalho docente hoje: elementos para um quadro de análise. In: TARDIF, Maurice; LESSARD, Claude. O trabalho docente: elementos para uma teoria da docência como profissão de interações humanas. Petrópolis - RJ: Vozes, 2009, p. 15-54.

VOSGERAU, Dilmeire Sant'Anna Ramos; ROMANOWSKI, Joana Paulin. Estudos de revisão: implicações conceituais e metodológicas. Rev. Diálogo Educ., Curitiba, v. 14, n. 41, p. 165-189, jan./abr. 2014. Disponível em: https://periodicos.pucpr.br/index.php/dialogoeducacional/article/view/2317 Acesso: 18 nov. 2020. 
Carlos César de Oliveira: Doutorando em Educação pela Pontifícia Universidade Católica do Rio de Janeiro - PUC Rio, Mestre em Educação pela Faculdade de Formação de Professores da Universidade do Estado do Rio de Janeiro - FFP/UERJ.

Orcid: https://orcid.org/0000-0003-0961-1695

E-mail: carlosoliveira.prof@smail.com

Helena Amaral da Fontoura: Doutora em Ciência pela Escola Nacional de Saúde Pública ENSP/Fundação Oswaldo Cruz, Pós Doutora em Educação na Universidade de Barcelona, Pós Doutora em Educação Universidade Federal de Mato Grosso. Professora Titular do Departamento de Educação da Faculdade de Formação de Professores da Universidade do Estado do Rio de Janeiro (FFP/UERJ).

Orcid: https://orcid.org/0000-0003-2795-8246

E-mail: helenafontoura@gmail.com

Este periódico utiliza a licença Creative Commons Attribution 3.0, para periódicos de acesso aberto (Open Archives Iniciative - OAI). 